\title{
Aegean Sea settlement design rules evolution
}

\author{
J. Theodoraki-Patsi \\ National Technical University of Athens, Greece
}

\begin{abstract}
The settlements in the Aegean Sea islands contain a variety of architectural properties, which are differentiated depending on their historical origin and their last domination of Franks, of Othomans or Greek authorities. Before the constitution of the contemporary Greek state, these properties were built based on common sense rules, deriving from the progressive evolution of building codes since antiquity, and which combined the Eastern tacit with the western codified knowledge.

Official design rules have existed since the $6^{\text {th }}$ century A.D. These have been assembled mainly by K. Harmenopoulos ( $14^{\text {th }}$ century A.D.) who composed the previous design rules in the "Exavivlos" code. These rules were rooted into the customary practices, providing equability of benefits between inhabitants.

Most islands of the Aegean Sea remained isolated up to the decade of the 1980 s, practicing these norms as customs, when under the motive of tourism, they began to be developed. With minimal exceptions, all the settlements of the Aegean Sea islands originated before the 20th century and consequently they have been shaped by pre-existing the modern period construction attitudes. The principles of these attitudes are summarized in four initial purposes that the built environment would have to fulfil: the compact and bounded layout, the view provision to all houses, the value of privacy and the facilitation of access to neighbours following the irregularities of topography. Today, a complicated legislative framework, although it is not efficiently implemented, results in restrictions and questionable mutations.
\end{abstract}

Keywords: design rule, Aegean Sea architecture, architectural evolution. 


\section{Introduction}

"The element has to belong to a system..... a particular element may appear in prescribed places. We are not allowed to arrange the elements of the system freely, but have to obey certain 'rule,'”.

Chr. Norberg-Schulz [1]

Each settlement of the Aegean Sea is the result of a final composition of a long run codified or uncodified set of building customs and rules that gave priorities to architectural principles according to the special circumstances of its creation. In some cases, the rule of compact and defensive layout prevails and in some others, the provision of a view or the ease of access is the dominant rule. The diversity of the natural characteristics on the other hand, shaped (in relation with the prevailing rule) a distinct building form. These building rules were developed and coded in the Eastern Mediterranean during a long span of time and were in effect up to the beginning of the 20th century, when the modern movement and the rapid increase of population imposed new principles, that mainly were applied in the urban centres. During the last two centuries, Greek architecture has been following a post-traditional design phase, concerning different neotraditional representations, while the recent legislative building framework is causing the emergence of a chaotic distribution of architectural elements. The purpose of the discussion about the original rules and principles is to question the current building legislative frame work [2] under the philosophy of the original patterns, in order to contribute [3] to the continuity [4] and authentic mutation of each particular historically built development.

With this preoccupation in mind, this presentation refers to the evolution of the small nucleated settlements of the Aegean Sea, going back to what might be claimed to be the first building principles.

\section{Historical evolution of building rules}

There are a number of design rules related to the position of settlements and houses in Greece that have been practiced since antiquity and that are documented on the ruins of the different archaeological sites [5].

Legislative codes are the early Byzantine era [6] official codes -The Eparchikon [7] and the Treatise of Julian of Ascalon (533 A.D) [8], providing rules for the land use, the view, the management of the waters and the flora. Later on, K. Harmenopoulos [9] (14 ${ }^{\text {th }}$ century) assembled the existing legislation (The Eparchikon [10] and the Treatise of Julian of Ascalon) in the "Exavivlos" code. "Exavivlos" was translated in many languages and constituted the base for the Greek speaking territory legislation, not only during the Ottoman period, but also for the modern Greek state. There are seventy one manuscript copies saved, from the 14 th until the 18 th century, eight printed publications, by the 16 th until $20^{\text {th }}$ century, seven translations in Latin, German, Russian, Rumanian, Bulgarian and English, from 16th until 18th century, and eight adaptations in Modern Greek, from the 16th until the19th century. In the second book, "Concerning trials and various 
innovations", there are included, apart from laws on economic subjects, regulations for building construction".

This code was primarily concerned with the maintenance of a level of equitability and flexibility and was widely used by the Church [11], providing performance requirements for the layout of buildings and the design of settlements. While it determined the infrastructure of Greek traditional architecture, it was combined with Arab authors' Treatises [12] and it was repeated during the Ottoman or Latin domination, surviving up to the 20th century and coexisting with the onset of neoclassicism in Greece [13].

The ordinances of this code shaped the built form of the Greek settlements up to the 20th century, when the vision of modernity introduced various concepts. They were implemented with simplicity, taking into consideration the smaller intervention and repercussion in the existing structures and contributing to the fair distribution of responsibilities and benefits between neighbours.

\section{Rules and principles}

By the phenomenological description of selective settlements of architectural form on islands of the Aegean Sea, it is obvious that the different representations of their built environment has been the result of an implementation of diverse architectural elements on a fabric that traces rules and practices existing for centuries.

Social practices as tacit codes, in relation to both the historical origin of each settlement and the local physical factors, resulted in a spectacular architectural variety. The dispersion of rules and principles can begin to account for both form and variability of social practices [14] in a vast region of Greek isles.

\subsection{Compact nucleated rule}

The oldest ordinance refers to the nucleated and compact settlements in such a way that the whole town forms a single unity, with the outer houses forming a compact wall (figs. 1 and 2) and all the houses built side by side, in lines.

The current legislative framework did not anticipate efficiently in order to keep construction to a limit, and the first tradition of nucleated and compact settlements is already rejected by a certain regulation to build in a delimited zone around the initial bounded form, that has resulted in a dispersed building expansion.

\subsection{View provision}

The provision of a view (figs. 3-5) for all houses and the anticipation for any new construction not to obstruct a direct view to a faraway vista was a principle historically fulfilled in any topography. In the rare examples of settling in the planes, the vista property was managed with an access to a terraced level.

Today, while a distant view is desirable for any property, this quality is included in the current legislative framework only for some exceptional surroundings of those declared as "Traditional" P.O/19.10.1978 settlements. 


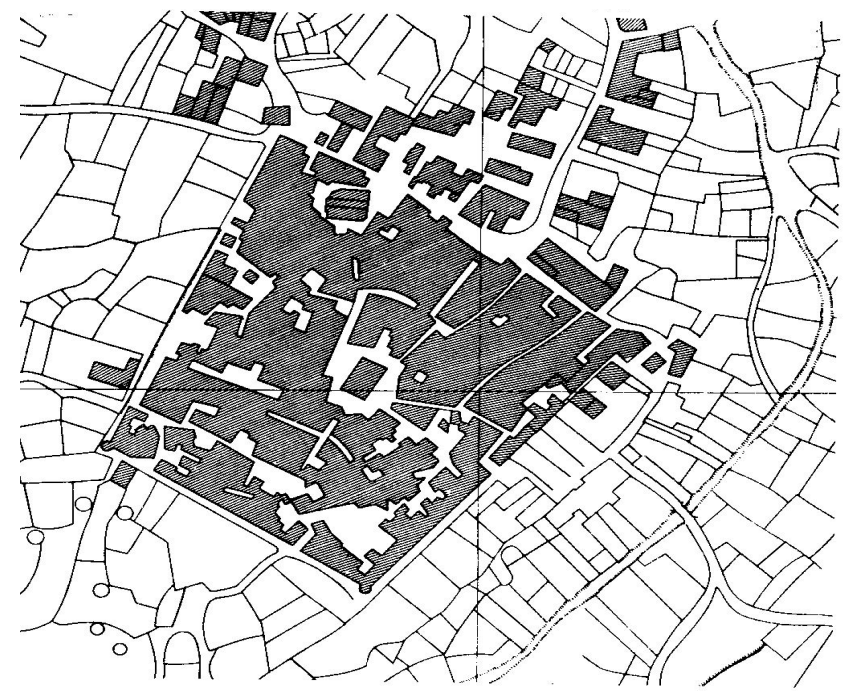

Figure 1: $\quad$ Plan of Kalamoti settlement, Chios islands [15].

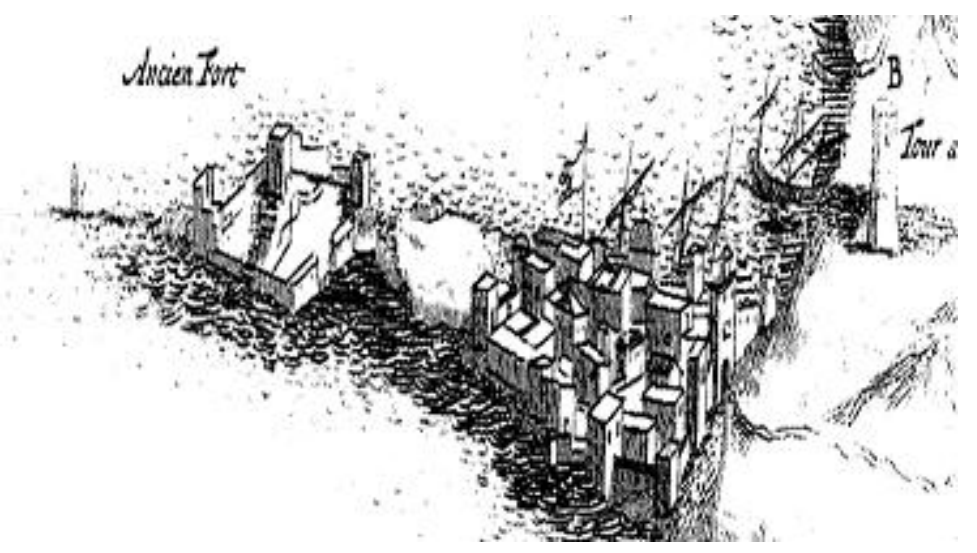

Figure 2: $\quad$ Chora of Andros island by Joseph de Tourneford, 1717 [16].

\subsection{Privacy}

A closed or semi-enclosed courtyard on the ground or on an upper floor level (fig. 6) was protecting the privacy of owners. This property was combined with the vista property and resulted to the evolution of the $\eta \lambda \imath \alpha \kappa o$ (sunlight) [17] room, that also contained projected enclosed balconies and verandas that would not have to overhang more than $1 / 3$ of the width of the road (fig.7).

The synthesis of the architectural elements intended to satisfy the privacy property is now days left to the design analysis of the individual architect engineer, who is introducing these elements freely and many times out of the original place. 


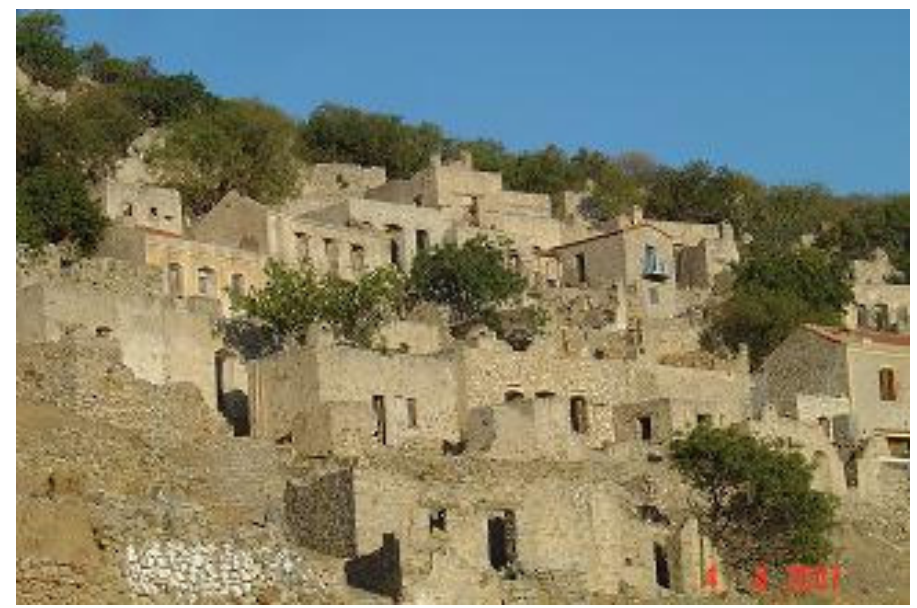

Figure 3: Micro Chorio in Tilos Island.

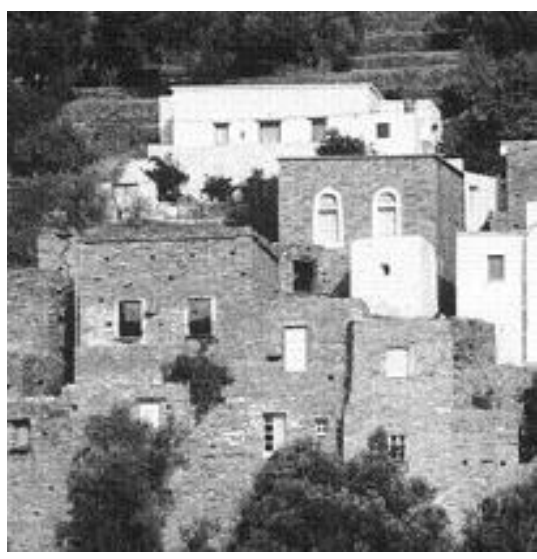

Figure 4: $\quad$ Korthi in Andros Island.

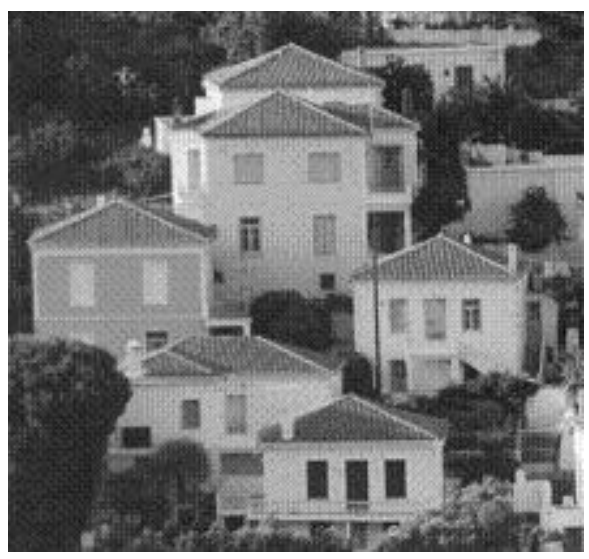

Figure 5: $\quad$ Stenies in Andros island.

\subsection{Irregular road system}

The circulation system was complicated and irregular (figs. 8-10) following the natural distributions of the topography and leading to dead ends, trespassing between houses, in order give access to every property and to confuse any intruder. Today, the irregular road pattern is sustained in the extensions plans of some settlements (ex. Spetses, Hydra) where the intrusion of cars is restricted.

On the contrary, in most cases a rectangular grid road system is emerging, in parallel with the destruction of the compact and nucleated form of the settlements. 


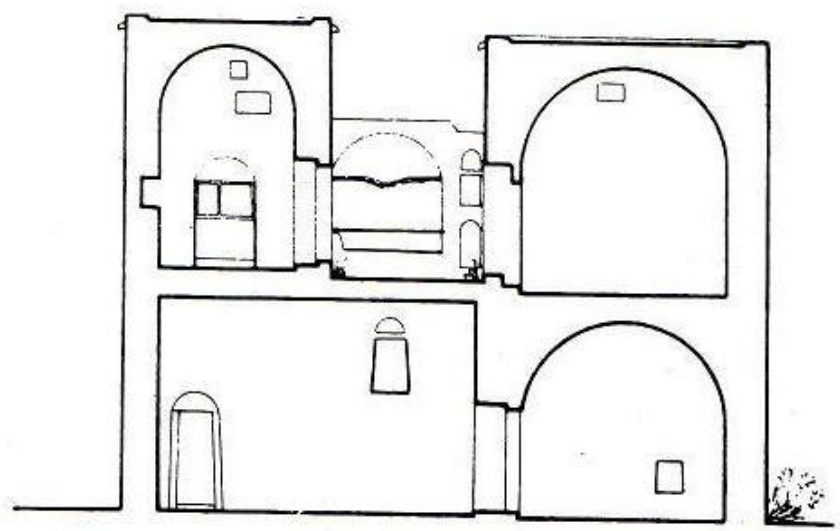

Figure 6: Semi-enclosed open space in the first floor, in Mesta, Chios Island [18].

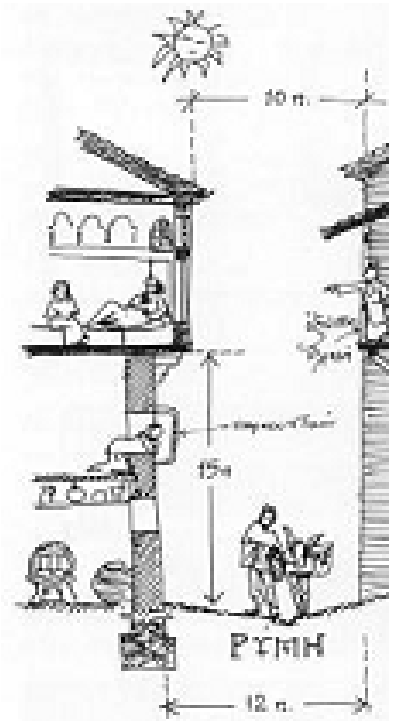

Figure 7: $\quad$ First floor enclosed projection [19].

\section{Final statement}

The principles of the nucleated character, the provision of view and privacy to every house, the irregular road system and the provision of access to neighbours, have been proved to be the rule for more than twelve centuries in the Byzantine and post Byzantine settlements of Aegean Sea. 

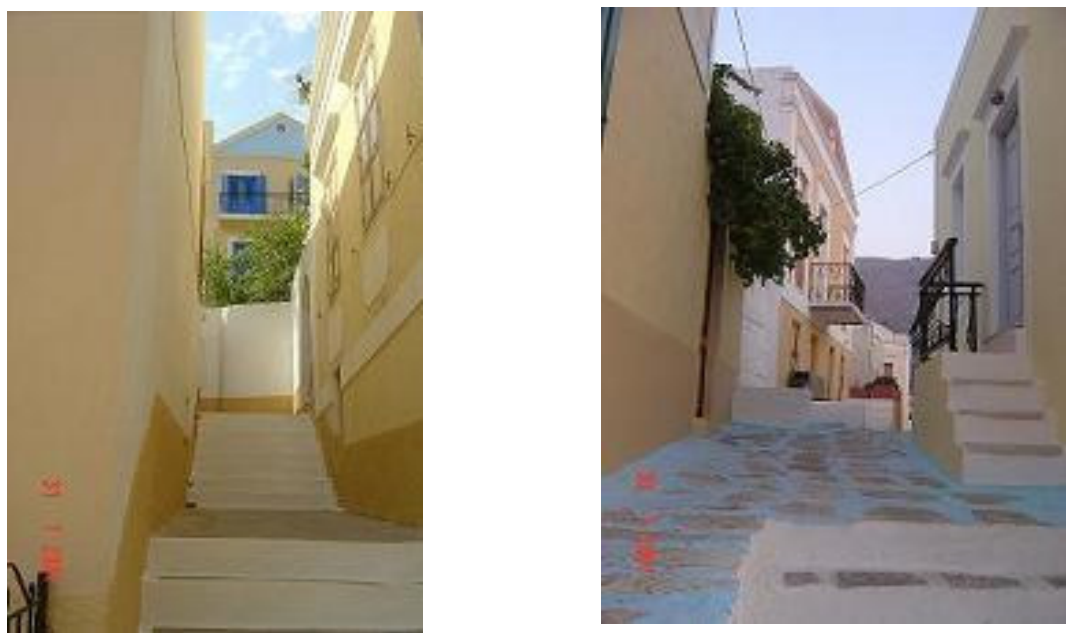

Figure 8: $\quad$ Access to houses in Symi Island.
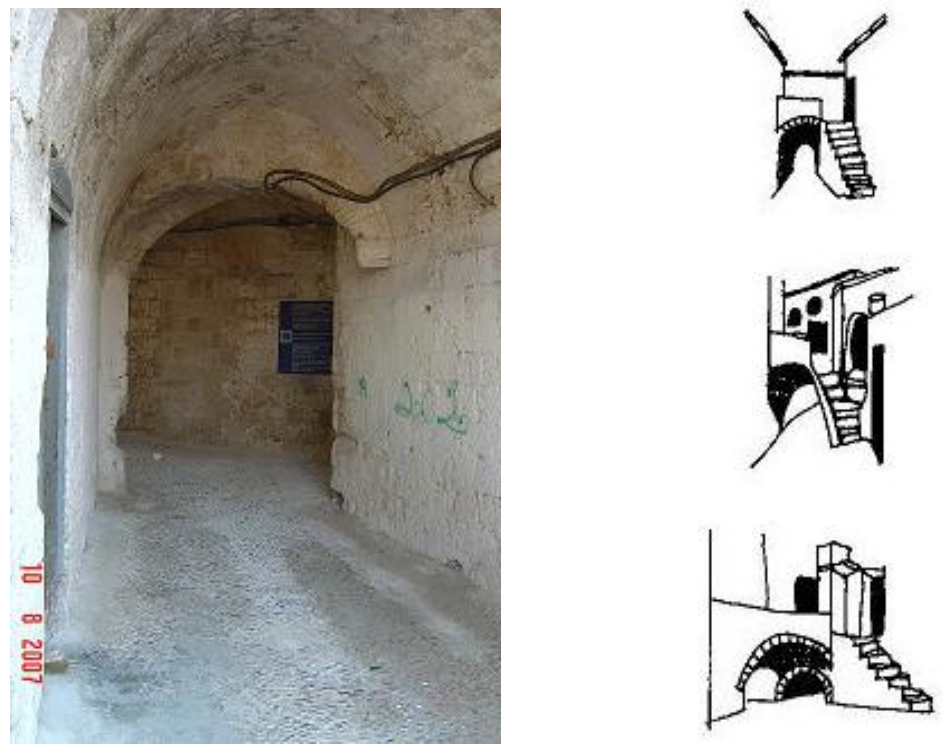

Figure 9: Bridge cover of a passage Figure 10: Accesses in Pytios, Chios to facilitate neighbour island [20]. access in Rhode Island.

In the Hellenic and the wider Mediterranean areas, the relationship between populations and cultures were composed of the different perceptions between east (cosmological order) and west (systematic order) for centuries, and they were imprinted on the built environment, which after years of development has 
today evolved into the present different architectural elements. There is obvious evidence that in some islands the tacit building principles were sustained uninterrupted during the post Byzantine period, as in the Cyclades that have remained more or less as they were, thanks to their insignificance and unproductive soil [21]. The Byzantine forms persisted, while the Latin Lords tolerated the Greek rites [22]. Local populations continued with their own priorities through customary rules and habits for the land distribution and the building construction [23].

The general principle of protecting the public interest and the integrity of each property was the base for the evolution of the tacit and explicit building codes in the Aegean Sea region for centuries. The implemented rules with emphasis on doing no harm to neighbours, on protecting the rights of the original usage, on privacy and on obligations concerning the protection of the environment, were introduced with clarity in the conscience of the post Byzantine Greek culture, during the Ottoman and Frank occupations, resulting in settlements of a human scale. The study of these rules continues offering lessons for building regulations aiming for a healthy and viable built environment which is under permanent renewal and development.

These design rules are also providing a useful tool in studying vernacular architecture, an issue that became updated under the topic of the current trend to create better places to live by regulating their aesthetics. The analysis of the historical system of codes, their implementation and survival, are important in understanding and learning in the prospect of producing greater building contexts. Contexts like the ones of the settlements of the Aegean Sea islands that were produced by explicit and implicit associations of ethical and customary values.

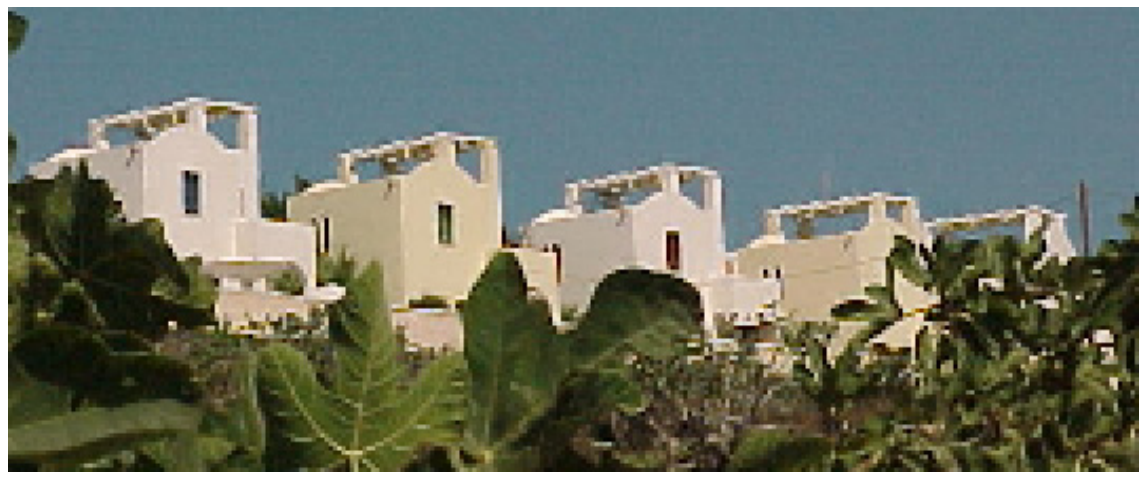

Figure 11: Architectural cloning in Santorini.

The principles of the Aegean Sea architecture were based for centuries on performance requirements that allowed the freedom with respect to actions and solutions within a framework of norms. In contrast, contemporary law prescriptions by a central authority, instead of promoting mutation of these rules, are producing homogeneity by cloning (Fig. 11) and transforming tacit norms to ambiguous explicit ones. 


\section{References}

[1] Chr. Norberg-Schulz, Intentions in architecture, MIT Press, 1965, p. 149.

[2] An enormous work have been done already during the last 30 years by the Ministry of Environmental Planning and Public Works as much as the Ministry of Culture, by recording the special architectural elements of each settlement and by legislating distinct building prescriptions for each settlement (P.O.24.4 /3.5.1985, P.O.20/30.8.85, P.O.25.4/16.5/1989, L. 250/97).

[3] As in a fibre optic, one can only and always have an idea of the source of given information at its terminal end: C. Poppi, Transcending time: Rethinking the invention of Tradition in R. Adam \& M. Hardy (ed.), Tradition Today, WIT press, Southampton, 2008, p. 17.

[4] As definite traditions of thought (continuity) in Chr. Tilley, Foucault: Towards an Archaeology of Archaeology, Reading material culture, Basil Blackwell Ltd., 1990, p. 293.

[5] Plato provided specific laws concerning the new towns. For the private houses ordered that must be arranged from the start in such a way the whole city may form a wall, according to E. Ben-Joseph, The code of The city, MIT press, Cambridge Massachusetts, 2005, p. 10.

[6] The ordinances of "Preference" ordered the rights of villager's property defending from the aristocracy impact, according S. Vryonis, Jr., The Byzantine Heritage into the official \& artistic culture of the Balcan peoples, Cultural Foundation of the National Bank of Greece (ed), The Byzantine Tradition after the fall of Constantinople, Athens, 1994, p. 41.

[7] The Byzantine emperor's Leon the Wise regulations were coded in the "Eparchikon Book" (9th century A.D.). It has been inspired by the work of the Emperor Ioustinian ( $4^{\text {th }}$ century A.D.).

[8] C. Saliou, Julian of Ascalon's treatise of construction and design rules from Sixth-Century Palestine.

[9] G. Pitsakis (ed.), K. Harmenopoulos, Exavivlos, Dodoni, Athens, 1971

[10] Discovered by Jules Nicole in a handwritten copy, entitled Cenevensis 23, of the 14th century claiming to be the original "Eparchikon Book". It was published under the precise title, Le livre du Prefet, L' edit de l' empereur Leon le sage sur les corporations de Constantinople Text grec du Genevensis 23, publie pour la premiere fois par Jules Nicole, Professeur de La Facullte des lettres de Geneve, avec une traduction latine, des notices exegetiques et critiques et des variantes du Cenevensis 23 au texte de Julian d' Ascalon, Georg \& Cie, Geneve, 1893.

[11] V. Tourptsoglou-Stefanidou, An outline of the byzantine building regulations, Eleftheroudakis, Athens, 2004.

[12] B. Hakim, Mediterranean urban and building codes: origins, content, impact and lessons, http://www.palgrave-journals.com/udi/journal/v13.n1. fig_tab/udi20084fl.html

[13] J. Theodoraki-Patsi, The imprint of cognitive evolution of a place, Ellikiki Epistimonologiki, Athens, 2008, p. 40. 
32 Structural Studies, Repairs and Maintenance of Heritage Architecture XI

[14] Chr. Tilley, Foucault: Towards an Archaeology of Archaeology, Reading material culture, Basil Blackwell Ltd., 1990, p. 338.

[15] Ministry of Transportation (ed), Topographical map, 1934.

[16] J. Piton de Tournefort, Relation d' un voyage au Levant, Imprimerie Royale, Paris, 1717, p.347.

[17] F. Koukoules, Byzantine life and culture, vol. D, Athens, 1951, p. 291.

[18] Ch. Bouras, Chios in Greek Traditional Architecture (Eastern Aegean, Sporades, Eptanissa), Melissa, Athens, 1989, p. 173.

[19] N. Moutsopoulos, Encorbellements architecturaux: Le "Sahnisin", Eteria Makedonikon Spoudon, Thessaloniki, 1988, p. 336.

[20] J. Theodoraki-Patsi, Architectural Identification in Chios island, N.T.U.A., Athens, 2000 [18]

[21] J. Th. Bent, The Cyclades or life among the insular Greeks, Longmans, Green \& Co, London, 1885, vii.

[22] Worshiped alla greca when Catholic priests were not available, in Slot B. J., Archipelagus Turbatus: Les Cyclades entre colonisation latine et occupation ottomane c. 1500-1718, Leiden 1982., cited in Speculum, vol.61, no 1(1986), p. 207.

[23] E. Marmaras, Cycladic settlements of the Aegean Sea: a blending of local and foreign influences Planning Perspectives 23:4, Routledge, 2008, p. 515. 